13

\title{
Пленки Ві-замещенных ферритов-гранатов для термомагнитной записи, фотоники и плазмоники: оптимизация условий синтеза с использованием сканирующей зондовой микроскопии
}

\author{
(C) А.Р. Прокопов, ${ }^{1}$ Т.В. Михайлова, ${ }^{1}$ Е.В. Данишевская, ${ }^{2}$ А.Н. Шапошников, ${ }^{1}$ В.Н. Бержанский, ${ }^{1}$ \\ А.В. Каравайников, ${ }^{1}$ А.С. Недвига, ${ }^{1}$ И.А. Наухацкий ${ }^{1}$, Е.Т. Милюкова ${ }^{1}$ \\ ${ }^{1}$ Крымский фредеральный университет им. В.И. Вернадского, \\ 295007 Симферополь, Россия \\ ${ }^{2}$ Крымский университет культуры, искусств и туризма, \\ 295017 Симферополь, Россия \\ e-mail: tatvladismikh@cfuv.ru
}

Поступило в Редакцию 28 марта 2019 г.

В окончательной редакции 28 марта 2019 г.

Принято к публикации 15 апреля 2019 г.

\begin{abstract}
Представлены результаты исследований по оптимизации режимов синтеза пленок Ві-замещенных ферритов-гранатов (Bi: IG) методами жидкофазной эпитаксии и вакуумного напыления с последующей кристаллизацией. Показано влияние параметра рассогласования между кристаллическими решетками пленки и подложки на функциональные свойства тонких монокристаллических высококоэрцитивных пленок Bi : IG. Проведена оптимизация режима высокотемпературного отжига напыленных пленок с целью формирования слоев с высокой концентрацией Ві для магнитофотонных и магнитоплазмонных структур. Установлено, что отжиг слоя $\mathrm{Bi}$ : IG под напыленным сверху слоем $\mathrm{SiO} 2$ позволит уменьшить шероховатость границ разделов в многослойных структурах.
\end{abstract}

Ключевые слова: Ві- замещенные ферриты-гранаты, режим синтеза, морфология поверхности, магнитооптические и магнитные свойства.

DOI: 10.21883/JTF.2019.11.48348.139-19

\section{Введение}

Область функционального применения микро- и наноразмерных пленок Ві-замещенных ферритов-гранатов (Bi : IG) постоянно расширяется при проектировании различных оптоэлектронных комплексов и устройств для передачи и обработки информации, оптических датчиков технического и медико-биологического назначения, визуализации магнитных полей благодаря существованию целого спектра доступных методов синтеза и их динамичному развитию [1-4]. На данный момент наиболее распространены методы жидкофазной эпитаксии (liquid phase epitaxy - LPE) [5-16], импульсного лазерного осаждения (pulsed laser deposition PLD) [17-21], радиочастотного распыления (radiofrequency sputtering - RFS) [22-24] и реактивного ионно-лучевого распыления (reactive ion beam sputtering - RIBS) [25-31].

Традиционный метод жидкофазной эпитаксии позволяет выращивать монокристаллические пленки Bi : IG для термомагнитной записи с низкой температурой Кюри $\left(T_{C}<100^{\circ} \mathrm{C}\right)$ и высокой коэрцитивностью $H_{C}$, созданной деформациями кристаллической решетки пленки при значительном рассогласовании периодов кристаллических решеток пленки $a_{f}$ и подложки $a_{s}$ [9-13]. Как было показано ранее с использованием оптических методов [8-15], параметр рассогласования $\Delta a=a_{f}-a_{s}$ оказывает большое влияние на морфологию и магнитные параметры эпитаксиальных пленок и определяет чувствительность пленок и пространственное разрешение записываемых реплик.

Синтез пленок $\mathrm{Bi}: \mathrm{IG}$ наноразмерной толщины и значительным замещением Вi, актуальных для целей интегральной оптики, фотоники и плазмоники, осуществлен методами вакуумного осаждения из паровой фазы [1-4,14-33]. Данные методы позволяют создать условия, при которых образование гранатовой фазы наиболее вероятно [25]. Для получения высококачественных гранатовых пленок необходимо соблюдение оптимального режима синтеза. Отклонение любого параметра процесса синтеза от оптимального значения приводит к формированию дефектов, образованию других кристаллических фаз или нестехиометричности состава. Метод PLD в основном используется для эпитаксиального роста in situ пленок и полностью гранатовых одномерных магнитофотонных кристаллов [17-21], RFS и RIBS для эпитаксиального роста in situ или синтеза посредством распыления и последующей кристаллизации пленок в кислороде или на атмосфере (post-annealing crystallization) [22-31]. Напыленные методами RFS и RIBS и кристаллизованные на воздухе пленки Bi : IG имеют поликристаллическую структуру, размеры зерен которой зависят от состава $\mathrm{Bi}$ : IG, температуры и длительности отжига, используемой подложки $[23,27,28,31]$. 
С целью создания интегральных устройств оптической обработки сигналов, совместимых с полупроводниковыми технологиями, большое внимание исследователей уделяется поиску оптимальной технологии синтеза наноразмерных пленок Bi : IG на негранатовых слоях и подложках [22,32]. С целью решения задачи кристаллизации слоев $\mathrm{Bi}$ : IG с содержанием Вi более 1 атома на формульную единицу на негранатовых подложках ряд авторов [4,29-31,33-35] предлагает двухэтапную технологию синтеза. В наших предыдущих исследованиях [29-31] была показана эффективность данного метода при создании структур магнитофотонных и магнитоплазмонных кристаллов с высокой магнитооптической (MO) активностью на основе зеркал Брэгга из $\mathrm{SiO}_{2}$ и $\mathrm{TiO}_{2}$. На слой $\mathrm{SiO}_{2}$, кварцевую подложку или подложку из оптически прозрачного ситалла наносится буферный слой (подслой) состава с меньшим содержанием Вi, например, $\mathrm{Bi}_{1.0} \mathrm{Y}_{0.5} \mathrm{Gd}_{1.5} \mathrm{Fe}_{4.2} \mathrm{Al}_{0.8} \mathrm{O}_{12}$. Затем, после кристаллизационного отжига буферного слоя проводятся напыление и кристаллизационный отжиг слоя с большим содержанием $\mathrm{Bi}$, например, $\mathrm{Bi}_{2.8} \mathrm{Y}_{0.2} \mathrm{Fe}_{5} \mathrm{O}_{12}$ или $\mathrm{Bi}_{1.5} \mathrm{Gd}_{1.5} \mathrm{Fe}_{4.5} \mathrm{Al}_{0.5} \mathrm{O}_{12}$.

В настоящей работе представлены исследования по поиску оптимальных параметров синтеза пленок Bi : IG, получаемых методом LPE при высоких значениях $\Delta a$, и методом RIBS с последующей кристаллизацией в процессе отжига. С использованием атомно-силовой (ACM) и магнитной силовой микроскопии (МСM) установлены оптимальный параметр $\Delta a$ микроразмерных эпитаксиальных пленок Bi : IG для термомагнитной записи и влияние высокотемпературного отжига на морфологию, доменную структуру и МО свойства наноразмерных пленок $\mathrm{Bi}$ : IG для фотоники и плазмоники. С целью снижения шероховатости многослойных наноструктур предложена технология закрытой кристаллизации граната под слоем $\mathrm{SiO}_{2}$.

\section{1. Оборудование и методы}

С целью исследования влияния параметра рассогласования $\Delta a$ на функциональные свойства тонких монокристаллических высококоэрцитивных пленок $\mathrm{Bi}: \mathrm{IG}$, выращенных методом LPE, и определения оптимального $\Delta a$ для термомагнитной записи был выбран состав Bi: IGhc с общей формулой $(\mathrm{Bi}, \mathrm{Lu}, \mathrm{Sm}, \mathrm{Ca})_{3}(\mathrm{Fe}, \mathrm{Ga}, \mathrm{Al}, \mathrm{Sc}, \mathrm{Zr})_{5} \mathrm{O}_{12}$. Пленки были синтезированы на монокристаллических подложках гадолиний-галлиевого граната $\mathrm{Gd}_{3} \mathrm{Ga}_{5} \mathrm{O}_{12}$ (GGG) кристаллографической ориентации (111). Увеличение $\Delta a$ было реализовано за счет изменения концентрации ионов $\mathrm{Bi}^{+3}$ и $\mathrm{Sm}^{+3}$. Параметр решетки пленок $a_{f}$ $\mathrm{Bi}$ : IGhc определяли с помощью рентгеновского дифрактометра ДРОН-3, химический состав - с помощью энергодисперсионного спектрометра ЭДС-1 на растровом электронном микроскопе РЭМ-106. Погрешность определения $a_{f}$ составила $0.02 \%$. Для исследуемых образцов $\Delta a$ варьировалась в диапазоне от 0.0070 до $0.0113 \mathrm{~nm}$, толщина пленок - от 4 до $5 \mu \mathrm{m}$. Разбавление диамагнитными ионами $\mathrm{Al}^{+3}, \mathrm{Ga}^{+3}$ и $\mathrm{Sc}^{+3}$ позволило снизить температуру Кюри $T_{C}$ до диапазона $55-90^{\circ} \mathrm{C}$. Оптимальный режим синтеза эпитаксиальной пленки для термомагнитной записи определялся нахождением оптимальных значений $\Delta a$, при которых $H_{C}$ максимальна, шероховатость поверхности и период метастабильной доменной структуры минимальны. В работе [15] было определено, что образцы с $\Delta a$ около $0.0099 \mathrm{~nm}$ наиболее чувствительны для записи с наименьшим пространственным периодом, а в работах $[9,10]$ представлена зависимость $H_{C}$ от $\Delta a$. Использование методов сканирующей зондовой микроскопии (С3М) позволило однозначно установить закономерности изменения рельефа поверхности пленок, размеры элементов столбчатой структуры и их корреляцию с $H_{C}$ и периодом доменной структуры.

Пленки Bi: IG наноразмерной толщины, используемые как MO слои магнитофотонных и магнитоплазмонных кристаллов, были получены методом RIBS [29-31]. Мишени для распыления составов $\mathrm{Bi}_{2.3} \mathrm{Dy}_{0.7} \mathrm{Fe}_{4.2} \mathrm{Ga}_{0.8} \mathrm{O}_{12} \quad$ (пленки $\mathrm{Bi}: \mathrm{IG} 1$ ), $\mathrm{Bi}_{1.0} \mathrm{Y}_{0.5} \mathrm{Gd}_{1.5} \mathrm{Fe}_{4.2} \mathrm{Al}_{0.8} \mathrm{O}_{12}$ (пленки $\mathrm{Bi}: \mathrm{IG} 2$ ) и $\mathrm{Bi}_{1.5} \mathrm{Gd}_{1.5} \mathrm{Fe}_{4.5} \mathrm{Al}_{0.5} \mathrm{O}_{12}$ (пленки $\mathrm{Bi}: \mathrm{IG} 3$ ) были изготовлены по традиционной керамической технологии [29]. Процесс осаждения слоев происходил в смеси аргона и кислорода на холодные подложки GGG, кальций-магний-цирконий-гадолиний-галлиевого граната $(\mathrm{Ca}, \mathrm{Mg}, \mathrm{Zr}, \mathrm{Gd})_{3} \mathrm{Ga}_{5} \mathrm{O}_{12}$ (CMZGGG) кристаллографической ориентации (111) и плавленого кварца. Осажденные пленки были аморфными и с целью их кристаллизации применялся отжиг на воздухе при атмосферном давлении и температурах $T_{a}$ более $600^{\circ} \mathrm{C}$. Выбор оптимального режима отжига осушествлялся по соответствию химического состава пленок составу мишеней, преобладанию доли гранатовой фазы, достижению максимального удельного фарадеевского вращения и минимальной шероховатости поверхности. Согласно предыдущим исследованиям [26], при длительности отжига $\tau_{a}=20$ min оптимальная $T_{a}$ для пленок $\mathrm{Bi}: \mathrm{IG} 1, \mathrm{Bi}: \mathrm{IG} 2$ и Bi : IG3 находится в диапазоне от 650 до $700^{\circ} \mathrm{C}$. Режим отжига с $T_{a}$ в диапазоне от 650 до $700^{\circ} \mathrm{C}$ и $\tau_{a}=20 \mathrm{~min}$ будем называть длительным низкотемпературным (longtime low-temperature - LLT) отжигом. В настоящей работе представлены результаты исследований влияния на свойства пленок $\mathrm{Bi}: \mathrm{IG}$ режима отжига с $T_{a}$ более $750^{\circ} \mathrm{C}$ и $\tau_{a}=3 \mathrm{~min}$, который далее будем называть кратковременным или быстрым высокотемпературным (rapid high-temperature - RHT) отжигом.

MO свойства пленок (угол фарадеевского вращения $\Theta_{\mathrm{F}}$, коэрцитивная сила $H_{C}$ и коэффициент прямоугольности $K_{P}$ ) были определены по магнитооптическим петлям гистерезиса (МОПГ), полученным нулевым компенсационным методом с использованием автоматизированного магнитополяриметра на длине волны $655 \mathrm{~nm}$. Толщину синтезированных пленок $h$ опреде- 
ляли с помощью модернизированного микроинтерферометра МИИ-4. Погрешность определения $h$ не превышала $10 \%$. Толщину наноразмерных пленок в процессе синтеза контролировали по времени распыления и предварительно определенной скорости осаждения [27-31]. Удельное фарадеевское вращение $\alpha_{\mathrm{F}}$ образцов рассчитывали, исходя из измеренных значений $\Theta_{\mathrm{F}}$ и $h$.

Топографию поверхности и доменную структуру пленок в размагниченном состоянии определяли с помощью C3M NTEGRA с оптической или универсальной измерительной головкой (NT-MDT, Россия) в полуконтактном режиме АСМ и МСМ. АСМ-измерения были проведены кантилеверами HA_HR. MCM изображения получены с использованием магнитных кантилеверов MFM01. ACM изображения для эпитаксиальных пленок были получены на участках площадью $225 \mu \mathrm{m}^{2}, \mathrm{MCM}-$ на участках $900 \mu \mathrm{m}^{2}$. АСМ изображения зернистых структур поверхностей наноразмерных пленок были получены на участке $4 \mu \mathrm{m}^{2}$ с использованием острого АСМ-зонда. Площадь МСМ изображений составила $225 \mu \mathrm{m}^{2}$. По АCM данным были определены параметр среднеквадратичной шероховатости поверхности $(R M S)$, размах высот $R_{\max }$ и средний размер поликристаллов у их основания $R_{\mathrm{pc}}$. Средний период доменной структуры $2 W$ был вычислен как среднее статистическое значение периодов доменной структуры, измеренных в разных сечениях МСМ изображения.

АСМ исследования поверхностей подложек перед синтезом пленок показали $R M S$ менее $0.3 \mathrm{~nm}$ для монокристаллических подложек GGG и $\mathrm{CMZGGG}$ и $0.8 \mathrm{~nm}$ для плавленого кварца.

\section{2. Результаты и обсуждение}

\section{1. Пленки Вi : IG для термомагнитной записи}

Поверхность пленок Bi : IGhc характеризуется сильно развитым рельефом и столбчатой структурой, что обусловлено значительной разницей параметров рассогласования кристаллических решеток пленки и подложки. На рис. 1 приведено, как изменяется блочная структура поверхности $(a-c)$ и доменная структура $(d-f)$ эпитаксиальных пленок $\mathrm{Bi}: \mathrm{IG} h c$ при изменении $\Delta a$. Представленная доменная структура получена размагничиванием образцов нагревом выше $T_{C}$. Такая доменная структура является метастабильной [8-16]. Параметры RMS образцов с $\Delta a=0.0070,0.0089,0.0099$ и $0.0113 \mathrm{~nm}$ составили $107.0,62.6,53.5$ и $374 \mathrm{~nm}$ соответственно. Средний размер характерных элементов столбчатой структуры для пленок составил 1.3, 0.6, 0.8 и $4 \mu \mathrm{m}$ соответственно. Для пленки с $\Delta a=0.0113 \mathrm{~nm}$ наблюдаются максимальные размеры элементов столбчатой структуры (вплоть до $10 \mu \mathrm{m})$. Следует отметить, что для параметра $R M S$ наблюдается обратная зависимость от значений $H_{C}$ - пленки с $\Delta a$ от 0.0084 до $0.0099 \mathrm{~nm}$ имеют наиболее высокую $H_{C}(60-77 \mathrm{Oe})$ среди всех
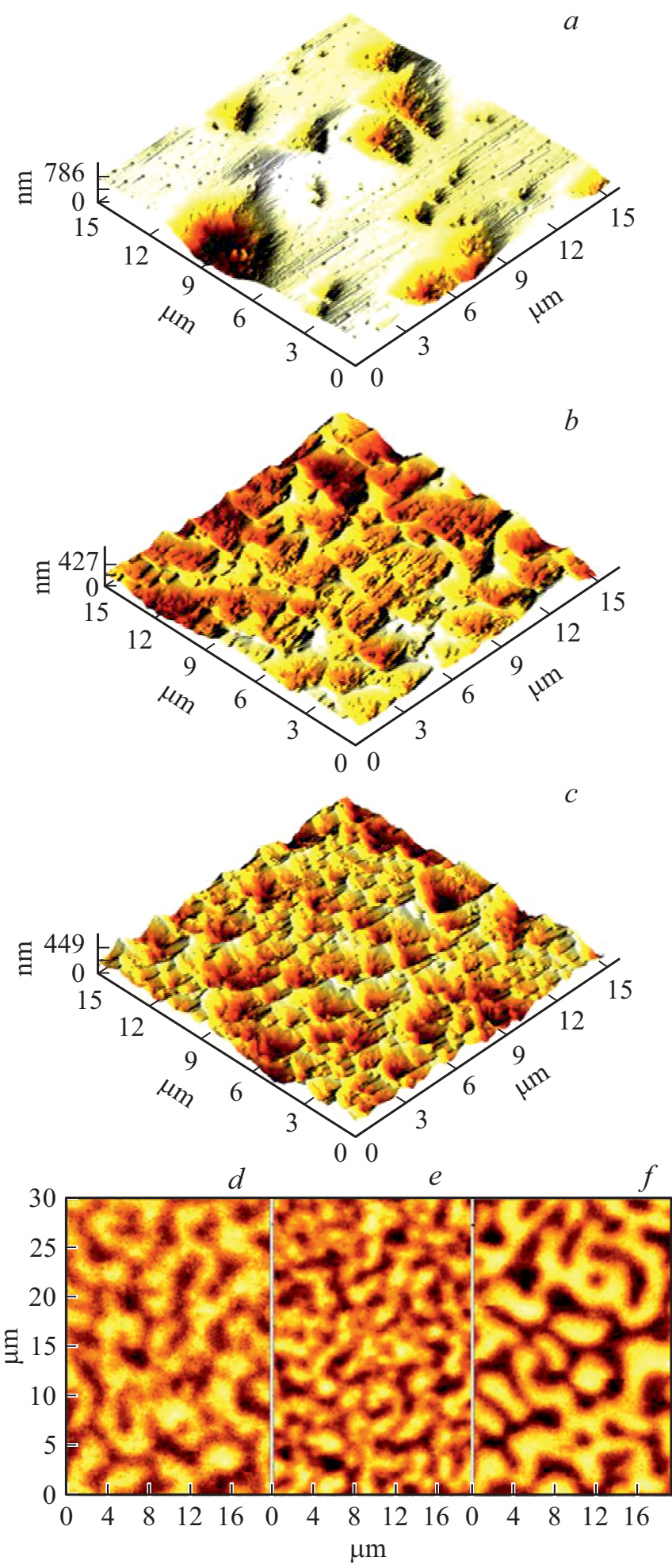

Рис. 1. АСМ изображения поверхности $(a-c)$ и МСМ изображения метастабильной доменной структуры $(d-f)$ эпитаксиальных пленок $\mathrm{Bi}: \mathrm{IG} h c$ при различных $\Delta a: 0.0070(a)$, $0.0089(b, d), 0.0099(c, e), 0.0105 \mathrm{~nm}(f)$.

исследованных образцов. Согласно МСМ данным, пленка с $\Delta a=0.0099 \mathrm{~nm}$ обладает наименьшим периодом 
Таблица 1. Параметры пленок Bi: IG1, синтезированных на подложках CMZGGG и GGG при разных температурах кристаллизационного отжига

\begin{tabular}{|c|c|c|c|c|c|c|c|c|c|}
\hline Подложка & $\begin{array}{c}\text { Шифр } \\
\text { образца }\end{array}$ & $T_{a},{ }^{\circ} \mathrm{C}$ & $\Theta_{\mathrm{F}},{ }^{\circ}$ & $\begin{array}{l}a_{\mathrm{F}}, \\
\circ / \mu \mathrm{m}\end{array}$ & $\begin{array}{l}2 W \\
\mu \mathrm{m}\end{array}$ & $\begin{array}{c}H_{C} \\
\text { Oe }\end{array}$ & $\begin{array}{c}R M S, \\
\mathrm{~nm}\end{array}$ & $\begin{array}{c}R_{\max }, \\
\mathrm{nm}\end{array}$ & $\begin{array}{c}R_{p c}, \\
\mathrm{~nm}\end{array}$ \\
\hline CMZGGG & $\begin{array}{l}\mathrm{Bi}: \mathrm{IG} 1-750(\mathrm{C}) \\
\mathrm{Bi}: \mathrm{IG} 1-800(\mathrm{C}) \\
\mathrm{Bi}: \mathrm{IG} 1-850(\mathrm{C})\end{array}$ & $\begin{array}{l}750 \\
800 \\
850\end{array}$ & $\begin{array}{l}0.39 \\
0.44 \\
0.34\end{array}$ & $\begin{array}{l}3.25 \\
3.67 \\
2.83\end{array}$ & $\begin{array}{l}2.09 \\
2.61 \\
2.66\end{array}$ & $\begin{array}{l}548 \\
487 \\
383\end{array}$ & $\begin{array}{r}6.7 \\
8.8 \\
15.4\end{array}$ & $\begin{array}{l}46.5 \\
68.9 \\
93.0\end{array}$ & $\begin{array}{r}85 \\
105 \\
150\end{array}$ \\
\hline GGG & $\begin{array}{l}\mathrm{Bi}: \mathrm{IG} 1-750(\mathrm{G}) \\
\mathrm{Bi}: \mathrm{IG} 1-800(\mathrm{G}) \\
\mathrm{Bi}: \mathrm{IG} 1-850(\mathrm{G})\end{array}$ & $\begin{array}{l}750 \\
800 \\
850\end{array}$ & $\begin{array}{l}0.40 \\
0.43 \\
0.35\end{array}$ & $\begin{array}{l}3.33 \\
3.58 \\
2.92\end{array}$ & $\begin{array}{l}2.52 \\
2.66 \\
3.29\end{array}$ & $\begin{array}{l}682 \\
609 \\
557\end{array}$ & $\begin{array}{r}5.6 \\
7.6 \\
13.5\end{array}$ & $\begin{array}{l}36.8 \\
59.8 \\
86.7\end{array}$ & $\begin{array}{r}95 \\
110 \\
175\end{array}$ \\
\hline
\end{tabular}

Таблица 2. Параметры кристаллизационного отжига и характеристики однослойных Bi : IG2 и двуслойных Bi : IG2 / Bi : IG3 пленок на подложках GGG и плавленого кварца

\begin{tabular}{|c|c|c|c|c|c|c|c|c|}
\hline Подложка & Шифр образца & $\Theta_{\mathrm{F}}{ }^{\circ}$ & $\alpha_{\mathrm{F}},{ }^{\circ} / \mu \mathrm{m}$ & $K_{\mathrm{P}}$, rel. units & $H_{C}, \mathrm{Oe}$ & $R M S, \mathrm{~nm}$ & $R_{\max }, \mathrm{nm}$ & $R_{p c}, \mathrm{~nm}$ \\
\hline \multicolumn{9}{|c|}{ RHT-отжиг $\left(T_{a}=800^{\circ} \mathrm{C} ; \tau_{a}=3 \mathrm{~min}\right)$} \\
\hline \multirow{2}{*}{ GGG } & $\mathrm{Bi}: \mathrm{IG} 2-R H T$ & 0.21 & 1.4 & 1 & 487 & 7.8 & 46.7 & 110 \\
\hline & $(\mathrm{Bi}: \mathrm{IG} 2 / \mathrm{Bi}: \mathrm{IG} 3)-R H T$ & 0.55 & 1.57 & 0.95 & 301 & 14.6 & 93.0 & 350 \\
\hline \multicolumn{9}{|c|}{ LLT-отжиг $\left(T_{a}=680-690^{\circ} \mathrm{C} ; \tau_{a}=20 \mathrm{~min}\right)$} \\
\hline \multirow{2}{*}{ GGG } & $\mathrm{Bi}: \mathrm{IG} 2-\operatorname{LLT}(\mathrm{G})$ & 0.19 & 1.27 & 1 & 437 & 3.3 & 21.4 & 45 \\
\hline & $\mathrm{Bi}: \mathrm{IG} 2-L L T / \mathrm{Bi}: \mathrm{IG} 3-L L T$ & 0.67 & 1.91 & 0.8 & 214 & 6.2 & 37.4 & 115 \\
\hline \multicolumn{9}{|c|}{ LLT-отжиг $\left(T_{a}=700^{\circ} \mathrm{C} ; \tau_{a}=20 \mathrm{~min}\right)$} \\
\hline Плавленый кварц & $\mathrm{Bi}: \mathrm{IG} 2-\operatorname{LLT}(\mathrm{FQ})$ & 0.05 & 0.71 & 1 & 852 & 9.1 & 117.8 & 90 \\
\hline \multicolumn{9}{|c|}{ LLT-отжиг $\left(T_{a}=700^{\circ} \mathrm{C} ; \tau_{a}=20 \mathrm{~min}\right)$ и RНT-отжиг $\left(T_{a}=800^{\circ} \mathrm{C} ; \tau_{a}=3 \mathrm{~min}\right)$} \\
\hline Плавленый кварц & - & 0.62 & 2.95 & 0.61 & 452 & 12.6 & 80.6 & 120 \\
\hline
\end{tabular}

$2 W=2.8 \mu \mathrm{m}$, что подтверждает результаты экспериментов по определению чувствительности пленок для термомагнитной записи сигналов [15]. Период $2 W$ образцов с $\Delta a=0.0089$ и $0.0105 \mathrm{~nm}$ составил 3.7 и $3.3 \mu \mathrm{m}$ соответственно.

\section{2. Пленки Bi : IG для фотоники и плазмоники}

C целью исследования влияния режима RHT-отжига на свойства пленок Bi : IG1 были синтезированы образцы с $h=120 \mathrm{~nm}$ на подложках GGG и CMZGGG при $T_{a}=750,800$ и $850^{\circ} \mathrm{C}$. В табл. 1 приведены параметры МОПГ, морфологии поверхности и средний период $2 W$ пленок. Коэффициент $K_{P}=1$ для всех образцов. Согласно АСМ данным, изменения морфологии с ростом $T_{a}$ аналогичны для пленок на GGG и CMZGGG. Первоначально мелкозернистая плотноупакованная структура поверхности пленок с увеличением $T_{a}$ постепенно становится крупноблочной с распределенными равномерно на поверхности отдельно стоящими кристаллитами. В исследованном диапазоне $T_{a}$ пленки с $T_{a}=800^{\circ} \mathrm{C}$ показали наилучшие характеристики (контраст МСМ изображений, высокое $\alpha_{\mathrm{F}}$, низкую $H_{C}$ ) при сравнительно небольшом росте параметра RMS. Значительное уменьшение $H_{C}$ и $\alpha_{\mathrm{F}}$ при достижении $T_{a}=850^{\circ} \mathrm{C}$ свидетельствует о значительной потере ионов $\mathrm{Bi}$ [25,26,33-35] в результате отжига пленки и возможном разрушении гранатовой фазы. Согласно МСМ измерениям, характер доменной структуры для пленок на подложках GGG и CMZGGG идентичный - лабиринтный. Контраст MCM изображений для образцов с $T_{a}=750$ и $800^{\circ} \mathrm{C}$ значительно отличался от наблюдаемого при $T_{a}=850^{\circ} \mathrm{C}$, что также свидетельствует об изменении магнитных характеристик пленок.

В табл. 2 приведены режимы отжига и измеренные параметры исследуемых образцов однослойных (Bi : IG2) и двуслойных (Bi : IG2/ Bi : IG3) пленок, синтезированных на подложке GGG при применении RHT- и LLT-отжига. Толщина однослойных пленок $\mathrm{Bi}$ : IG2 составляла $150 \mathrm{~nm}$. Для двуслойных пленок Bi : IG2 / Bi : IG3 толщина второго слоя Bi : IG3 составляла $200 \mathrm{~nm}$. Технология синтеза двуслойных образцов была различной для RHT- и LLT-отжига. RHT-отжиг был применен для полностью аморфной двуслойной пленки Bi : IG2 / Bi : IG3, полученной последовательным 


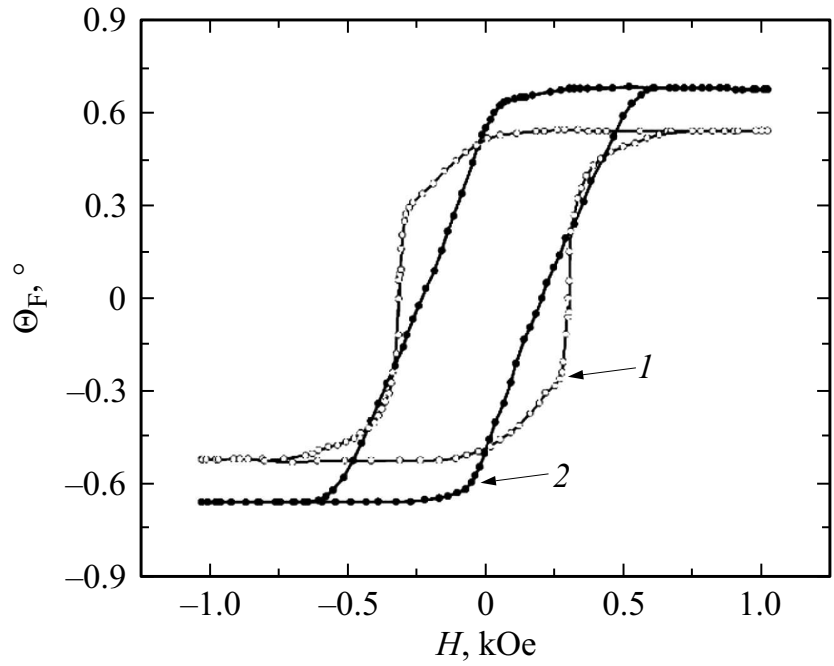

Рис. 2. МОПГ двуслойных пленок (Bi: IG2 / Bi : IG3) - RHT (1) и Bi : IG2 - LLT / Bi : IG3 - LLT (2) на подложке GGG.
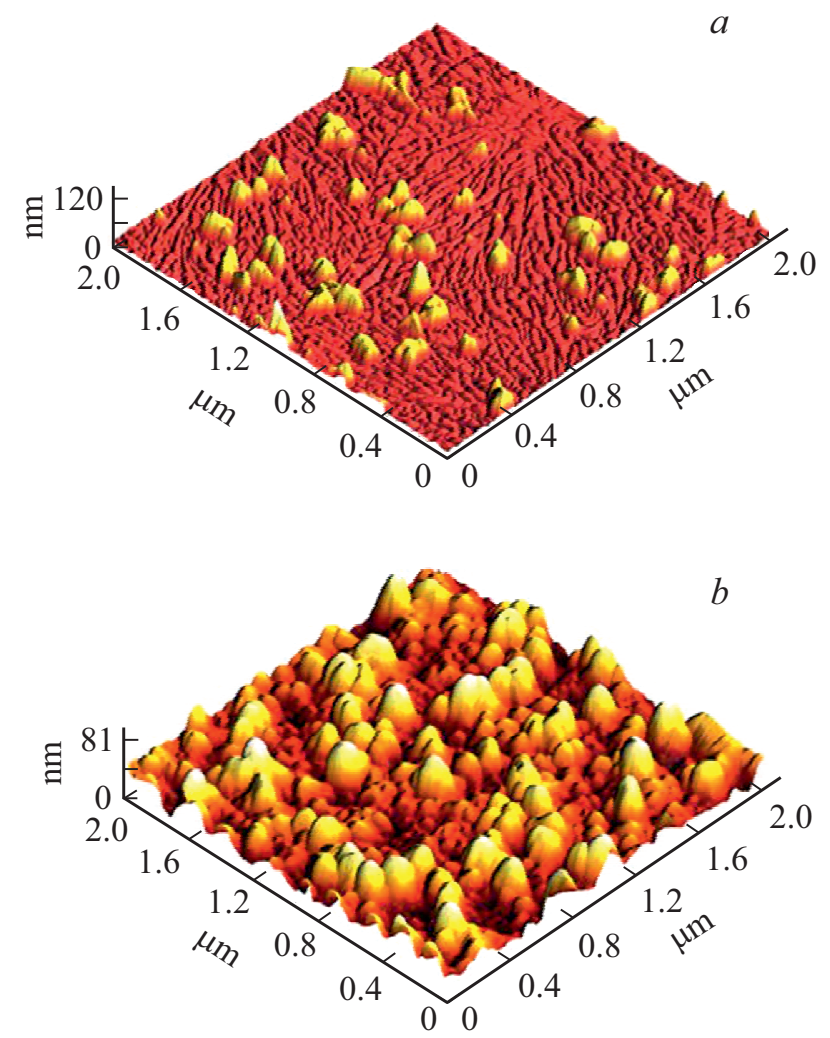

Рис. 3. АСМ изображения поверхности однослойной $\mathrm{Bi}: \mathrm{IG} 2$ - LLT(FQ) (a) и двуслойной Bi : IG2 - LLT / Bi : IG3 - RHT (b) пленок на подложке плавленого кварца.

напылением слоев, с целью снижения потерь гранатообразующих элементов в процессе отжига при высоких температурах.

Двуслойная пленка GGG / Bi : IG2-LLT / Bi : IG3-LLT была получена в два этапа: напылением и LLT-отжигом слоя Bi: IG2 с последующими напылением и LLTотжигом слоя Bi : IG3. Увеличение размеров кристаллитов и более развитая поверхность для RHT-отожженных пленок по сравнению с LLT-отожженными пленками свидетельствуют о быстром росте кристаллитов при RHT-отжиге. На рис. 2 показано отличие МОПГ двуслойных образцов, синтезированных при RHT- и LLTотжиге. RHT-отжиг снижает $\alpha_{\mathrm{F}}$ по сравнению с оптимальным режимом LLT-отжига, что указывает на потерю Ві в составе образованного граната. Сложный характер МОПГ образца с RHT-отжигом свидетельствует о том, что слои пленки не связаны обменным взаимодействием и их перемагничивание происходит независимо. МОПГ образца с LLT-отжигом демонстрирует простую форму и наличие обменной связи между кристаллизованными слоями Вi : IG2 и Bi : IG3.

Опираясь на полученные результаты, с целью эффективной кристаллизации двуслойной пленки $\mathrm{Bi}$ : IG2 / Bi : IG3 на слоях $\mathrm{SiO}_{2}$ или кварцевых подложках было предложено использовать LLT-отжиг для первого слоя Вi : IG2 и RHT-отжиг для второго слоя $\mathrm{Bi}$ : IG3. Толщины слоев Bi : IG2 и Вi : IG3 составляли 70 и $140 \mathrm{~nm}$ соответственно. В табл. 2 приведены режимы отжига и измеренные параметры исследуемых образцов на подложке плавленого кварца. АСМ изображения поверхности образцов представлены на рис. 3. Следует отметить, что кристаллизация с применением
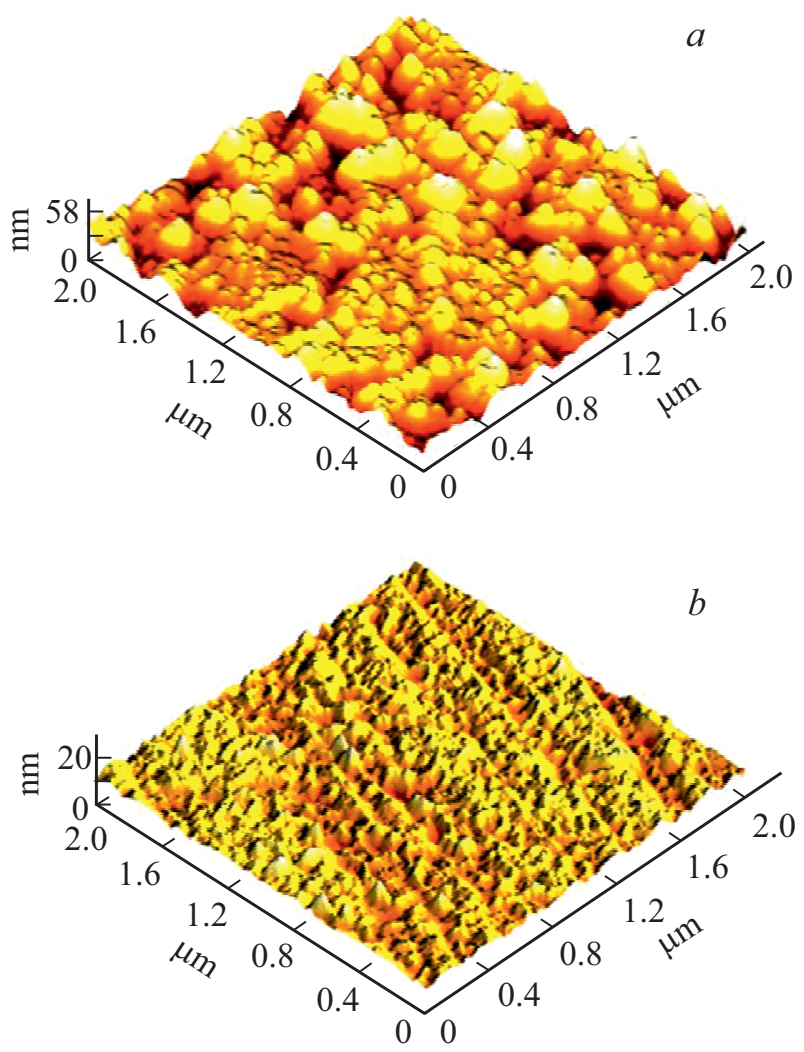

Рис. 4. АСМ изображения поверхности однослойной $\mathrm{Bi}:$ IG3 $(a)$ и двуслойной $\mathrm{Bi}: \mathrm{IG}_{3} / \mathrm{SiO}_{2}(b)$ пленок на подложке GGG. 
Таблица 3. Характеристики однослойной Bi : IG3 и двуслойной $\mathrm{Bi}: \mathrm{IG} 3 / \mathrm{SiO}_{2}$ пленок на подложках GGG

\begin{tabular}{c|c|c|c|c|c}
\hline Шифр образца & $\Theta_{\mathrm{F}},{ }^{\circ}$ & $\alpha_{\mathrm{F}},{ }^{\circ} / \mu \mathrm{m}$ & $K_{P}$, a.u. & $H_{C}, \mathrm{Oe}$ & $R M S, \mathrm{~nm}$ \\
\hline $\mathrm{Bi}: \mathrm{IG} 3$ & 0.43 & 3.07 & 0.73 & 199 & 7.6 \\
$\mathrm{Bi}: \mathrm{IG} 3 / \mathrm{SiO}_{2}$ & 0.32 & 2.29 & 0.6 & 210 & 1.4
\end{tabular}

RHT-отжига второго слоя Bi : IG3 приводит к росту $\alpha_{\mathrm{F}}$ в сравнении с образцами Bi : IG2-HT и Bi : IG2-LLT на GGG. Последнее свидетельствует о преимуществе использования последовательной кристаллизации путем LLT-отжига подслоя с меньшим содержанием $\mathrm{Bi}$ и RHT-отжига основного слоя с большим содержанием Ві для формирования двуслойных пленок с высокой концентрацией Ві для магнитофотонных и магнитоплазмонных структур.

C целью снижения параметра RMS при изготовлении многослойных структур была предложена методика „закрытого“ синтеза гранатового слоя. Идея эксперимента заключалась в осуществлении „блокирования“ разрастания кристаллитов при отжиге пленки Bi : IG после нанесения на нее аморфного негранатового слоя. Для исследований были синтезированы однослойная Bi : IG3 и двуслойная $\mathrm{Bi}: \mathrm{IG} 3 / \mathrm{SiO}_{2}$ пленки на подложках GGG. Толщина слоев граната в обоих образцах составляла $140 \mathrm{~nm}$, толщина слоя $\mathrm{SiO}_{2}-100 \mathrm{~nm}$. Кристаллизационный отжиг проводили в LLT-режиме. Характер морфологии поверхности образцов (рис. 4) указывает на образование агломератов зерен в пленках гранатов. Сравнение параметров $R M S$ поверхности одно- и двуслойной пленок, их магнитные и МО характеристики представлены в табл. 3. Из полученных данных (в том числе кадров размером больше $4 \mu \mathrm{m}^{2}$ ) можно сделать вывод, что в случае применения совместного кристаллизационного отжига слоя Bi : IG и расположенного над ним слоя $\mathrm{SiO}_{2}$ значения параметров шероховатости слоя $\mathrm{SiO}_{2}$ меньше в 3-5 раз, чем значения тех же параметров для слоя $\mathrm{Bi}$ : IG. В случае сравнения поверхности слоя $\mathrm{SiO}_{2}$ на слоях $\mathrm{Bi}: \mathrm{IG}$, кристаллизованных отдельно на воздухе и совместно под $\mathrm{SiO}_{2}$, параметр $R M S$ снижается только в 2-3 раза. Удельное фарадеевское вращение $\alpha_{\mathrm{F}}$ граната при закрытой кристаллизации без доступа кислорода снижается на $25 \%$ по сравнению с кристаллизацией на воздухе, что свидетельствует о возможной нестехиометрии состава граната по кислороду.

\section{Заключение}

Методами СЗМ исследованы морфология поверхности и доменная структура высококоэрцитивных эпитаксиальных пленок Bi : IG для термомагнитной записи. Показано, что пленки с параметром рассогласования кристаллических решеток пленки и подложки $\Delta a$ от 0.0084 до $0.0099 \mathrm{~nm}$ обладают наибольшей ко- эрцитивностью, наименьшим периодом метастабильной доменной структуры и имеют поверхность с наименьшими по размеру элементами столбчатой структуры и шероховатостью, что делает их оптимальными для термомагнитной записи.

С использованием методов АСМ и МСМ для наноразмерных пленок $\mathrm{Bi}: \mathrm{IG}$, используемых в качестве $\mathrm{MO}$ слоев фотонных и плазмонных наноструктур, установлено, что:

- повышение температуры отжига $T_{a}$ от 750 до $850^{\circ} \mathrm{C}$ при длительности отжига $\tau_{a}=3 \mathrm{~min}$ (RHT-отжиг) приводит к увеличению размеров кристаллитов и периода доменной структуры пленок, а оптимальная $T_{a}$ составляет $800^{\circ} \mathrm{C}$;

- шероховатость поверхности однослойных и двуслойных пленок $\mathrm{Bi}$ : IG увеличивается в 2.4 раза при применении RHT-отжига в сравнении с режимом отжига при $T_{a}$ в диапазоне от 650 до $700^{\circ} \mathrm{C}$ и $\tau_{a}=20 \mathrm{~min}$ (LLT-отжиг).

Предложены две методики синтеза пленок $\mathrm{Bi}$ : IG для магнитофотонных и магнитоплазмонных структур: последовательная кристаллизация двуслойных пленок с высокой концентрацией Bi путем LLT-отжига подслоя с меньшим содержанием Вi и RHT-отжига основного слоя с бо́льшим содержанием Ві и „закрытая“ кристаллизация $\mathrm{Bi}$ : IG под напыленным сверху слоем $\mathrm{SiO}_{2}$.

Показано, что предложенные технологии синтеза позволят уменьшить шероховатость границ разделов в многослойных структурах. Эффективность применения последовательной кристаллизации двуслойных пленок подтверждается также достижением высоких значений угла фарадеевского вращения.

\section{Финансирование работы}

Исследования выполнены при финансовой поддержке Министерства науки и высшего образования Российской Федерации в рамках базовой части государственного задания (номер проекта 3.7126.2017/8.9) и в рамках поддержанного федеральным государственным автономным образовательным учреждением высшего образования „Крымский федеральный университет им. В.И. Вернадского“ гранта № ВГ13/2018.

\section{Конфликт интересов}

Авторы заявляют, что у них нет конфликта интересов.

\section{Список литературы}

[1] Inoue M., Baryshev A.V., Goto T., Baek S.M., Mito S., Takagi H., Lim P.B. In: Magnetophotonics / Ed. by M. Inoue, M. Levy, A.V. Baryshev. Berlin, Heidelberg: Springer-Verlag, 2013. P. 163.

[2] Lyubchanskii I.L., Dadoenkova N.N., Lyubchanskii M.I., Shapovalov E.A., Rasing Th. // J. Phys. D: Appl. Phys. 2003. Vol. 36. P. R277-R287. 
[3] Inoue M., Fujikawa R., Baryshev A., Khanikaev A., Lim P.B., Uchida H., Aktsipetrov O., Fedyanin A., Murzina T., Granovsky A. // J. Phys. D: Appl. Phys. 2006. Vol. 39. R151-R161.

[4] Berzhansky V.N., Karavainikov A.V., Mikhailova T.V., Prokopov A.R., Shaposhnikov A.N., Shumilov A.G., Lugovskoy N.V., Semuk E.Y., Kharchenko M.F., Lukienko I.M., Kharchenko Yu.M., Belotelov V.I. // JMMM. 2017. Vol. 440. P. 175-178.

[5] Fratello V.J., Licht S.J., Brandle C.D., O'Bryan H.M., Baiocchi F.A. // J. Cryst. Growth. 1994. Vol. 142. N 1-2. P. 93.

[6] Hansen P., Witter K. // J. Appl. Phys. 1985. Vol. 58. N 1. P. 454.

[7] Prokopov A.R., Vetoshko P.M., Shumilov A.G., Shaposhnikov A.N., Kuz'michev A.N., Koshlyakova N.N., Berzhansky V.N., Zvezdin A.K., Belotelov V.I. // J. Alloy Compd. 2016. Vol. 671. P. 403-407.

[8] Vishnevskii V., Nesteruk A., Nedviga A., Dubinko S., Prokopov A. // Sens. Lett. 2007. Vol. 5. P. 29.

[9] Дубинко С.В., Недвига А.С., Вишневский В.Г., Шапошников А.Н., Ягупов В.С., Нестерук А.Г., Прокопов А.Р. // Письма в ЖТФ. 2005. Т. 31. Вып. 22. С. 68. [Dubinko S., Nedviga A., Vishnevskii V., Shaposhnikov A., Yagupov V. Nesteruk A., Prokopov A. // Tech. Phys. Lett. 2005. Vol. 31. P. 979.]

[10] Berzhansky V., Nedviga A., Vishnevskii V., Prokopov A. // Sol. St. Phen. 2009. Vol. 152-153. P. 11.

[11] Berzhansky V.N., Vishnevskii V.G., Nedviga A.S., Nesteruk A.G. // J. Magn. 2009. Vol. 14. N 3. P. 108.

[12] Berzhansky V.N., Vishnevskii V.G., Milyukova H.T., Nedviga A.S., Nesteruk A.G., Danishevskaya H.V. // Acta Phys. Pol. A. 2010. Vol. 118. P. 864-866.

[13] Вишневский В.Г., Недвига А.С., Нестерук А.Г., Бержанский В.Н., Дударенко И.В. // Ученые записки Таврического национального университета им. В.И. Вернадского. Серия „Физико-математические науки“. 2010. Т. 23 (62). № 1. Ч. I. C. $158-173$.

[14] Высоких Ю.Е., Краснобородько С.Ю., Шевяков В.И., Бержанский В.Н., Михайлова Т.В., Шапошников А.Н., Прокопов А.Р., Недвига А.С. // Изв. вузов. Электроника. 2017. T. 22. № 6. C. 596-601.

[15] Berzhansky V., Danishevskaya Y., Nedviga A., Bektemirova M. // J. Phys. Conf. Ser. 2018. Vol. 1124. 061006.

[16] Danishevskaya Y.V., Krikun A.S., Nedviga A.S., Mikhailova T.V., Berzhansky V.N. // J. Phys. Conf. Ser. 2017. Vol. 917. 072004.

[17] Chern M.-Y., Liaw J.-S. // Jpn. J. Appl. Phys. 1997. Vol. 36. P. 1049.

[18] Kahl S., Grishin A.M. // Appl. Phys. Lett. 2004. Vol. 84. P. 1438.

[19] Dzibrou D.O., Grishin A.M. // J. App. Phys. 2009. Vol. 106. P. 043901.

[20] Leitenmeier S., Koerner T., Griesbauer J., Herbort M. // J. Cryst. Growth. 2008. Vol. 310. P. 5392-5401.

[21] Veis M., Lišková E., Antoš R., Višňovský Ц̆., Kumar N., Misra D.S., Venkataramani N., Prasad S., Krishnan R. // Thin Solid Films. Vol. 519. P. 8041.

[22] Gomi M., Tanida T., Abe M. // J. Appl. Phys. 1985. Vol. 57. N 8. P. $3888-3890$.

[23] Suzuki T. // J. Appl. Phys. 1991. Vol. 69. P. 4756-4760.

[24] Nur-E-Alam M., Vasiliev M., Alameh K., Kotov V. // Adv. Opt. Technol. 2011. Vol. 2011. 971267.
[25] Okuda T., Koshizuka N., Hayashi K. etal. // IEEE Tr. Magn. 1987. Vol. 23. N 5. P. 3491.

[26] Berzhansky V.N., Shaposhnikov A.N., Prokopov A.R., Karavainikov A.V., Mikhailova T.V., Semuk E.Yu., Sharipova M.I., Dolgova T.V., Fedyanin A.A., Kotov V.A., Golub V.O. // Mat.-wiss. u. Werkstofftech. 2011. Vol. 42. N 1. P. 19.

[27] Shaposhnikov A.N., Prokopov A.R., Berzhansky V.N., Karavainikov A.V., Vysokikh Y.E., Gerasimenko N.N., Smirnov D.I. // Mater. Res. Bull. 2017. Vol. 95. P. 115-122.

[28] Shaposhnikov A.N., Prokopov A.R., Karavainikov A.V., Berzhansky V.N., Mikhailova T.V., Kotov V.A., Balabanov D.E., Sharay I.V., Salyuk O.Y., Vasiliev M., Golub V.O. // Mater. Res. Bull. 2014. Vol. 55. P. 19-25.

[29] Mikhailova T.V., Berzhansky V.N., Shaposhnikov A.N., Karavainikov A.V., Prokopov A.R., Kharchenko Yu.M., Lukienko I.M., Miloslavskaya O.V., Kharchenko M.F. // Opt. Mater. 2018. Vol. 78. P. 521-530.

[30] Mikhailova T.V., Lyashko S.D., Tomilin S.V., Karavainikov A.V., Prokopov A.R., Shaposhnikov A.N., Berzhansky V.N.// J. Phys. Conf. Ser. 2017. Vol. 917. 062053.

[31] Бержсанский В.Н., Шапошников А.Н., Прокопов А.Р., Каравайников А.В., Михайлова Т.В., Лукиенко И.Н., Харченко Ю.Н., Голуб В.О., Салюк О.Ю., Белотелов В.И. // ЖЭТФ. 2016. Т. 150. Вып. 5. С. 859. [Berzhansky V.N., Shaposhnikov A.N., Prokopov A.R., Karavainikov A.V., Mikhailova T.V., Lukienko I.N., Kharchenko Yu.N., Golub V.O., Salyuk O.Yu., Belotelov V.I. // J. Exp. Theor. Phys. 2016. Vol. 123. P. 744-751.]

[32] Onbasli M.C., Goto T., Sun X., Huynh N., Ross C.A. // Opt. Express. 2014. Vol. 1. P. 25184.

[33] Okuda T., Katayama T., Satoh K., Yamamoto H. // J. Appl. Phys. 1991. Vol. 69. N 8. P. 4580.

[34] Toraya H., Okuda T. // J. Phys. Chem. Solids. 1995. Vol. 56. N 10. P. 1317.

[35] Okuda T., Kudox A., Yoshihara S. etal. // J. Phys. IV France. 1997. Vol. 7. P. C1-707. 